\title{
Knowledge about Waiting Time Spent in the Emergency Department for Patients in Saudi Arabia and Overall Patient Satisfaction
}

\author{
Abdulrahman Saeed Saad Alharbi ${ }^{1}$, Adnan Meteb Mohamed Almezani ${ }^{1}$, Ayman Mamdouh \\ Alrashdi ${ }^{1}$, Hisham Mohammed Almomen ${ }^{2}$ \\ College of Medicine University of Hail ${ }^{1}$, Gulf Medical University Ajman, UAE ${ }^{2}$ \\ Corresponding author: Abdulrahman Saeed Saad Alharbi, E-mail: abdulrahmansaeed64@yahoo.com, \\ Phone no: +966540956098
}

\begin{abstract}
Background: Despite the modern society and medical services, waiting in emergency department is taking too long time for patients in Saudi Arabia. Time spent in the emergency department is crucial and can affect the overall health outcomes. Knowing the time spent in the emergency department and overall patient's satisfaction can provide an important information of health care that is provided in Saudi Arabia. Comparing the time spent in the emergency department in Saudi Arabia to other countries will help us know the quality of health care provided.

Objectives: Waiting in the emergency department is a global issue not only in the developing countries but also in modern countries. This study aimed at assessing how long is the waiting time spent by patients in the emergency department before receiving the medical care and the overall patients' satisfaction. Methods: A cross-sectional study on the time spent in the emergency department before getting help for patients in Saudi Arabia and overall patients' satisfaction was carried out on 528 participants during the period from February to March 2018. Results: $42 \%$ of the participants, indicated that the main complain that brought them to the emergency department was in the abdominal area and $29.5 \%$ of the patients spent more than one hour before getting helped from healthcare providers. $18.8 \%$ of the participants evaluated the emergency department service by 1 out of 10. Conclusion: Our results showed that large number of patients was suffering from waiting too long time in the emergency department before receiving the required medical care.
\end{abstract}

Keywords: Emergency department, waiting time, Evaluation.

\section{INTRODUCTION}

A hospital is a combination of a social and medical organization which functions to provide complete healthcare in a professional way to the patients through both curative and preventive means. Hospitals are an important facility in the community and an essential center for training the health care workers ${ }^{(5)}$. An emergency department (ED) should offer a fast care for the acutely ill or injured persons that require the attention of specialized nurses and physicians. Emergency department (ED) crowding in the Saudi Arabia has increased significantly these years the same as other countries around the world. Across the United States of America, an ambulance is diverted away from an overcrowded ED approximately once every minute ${ }^{(1)}$. Patients who do arrive in the ED have faced increasingly long average wait times and ED visit increased over the past decade ${ }^{(2,3)}$. Most importantly, this increase has been obvious for patients with the most acute illnesses that need to receive care of their illness $(2,3,4)$. In 2006, the average wait time for emergent patients to acquire an ED provider was 37 minutes, which is above recommended maximum time of 15 minutes ${ }^{(4)}$. Patients who go to the emergency departments often experience a long waiting time. Waiting is usually due to the triage process which is requested for hospital admission, waiting for a bed for the patients, a shortage of the on-call physicians and an overcrowded emergency department due to a disaster accidents. Because of emergency waiting time can lead to a delay in treating and handling patients who need an immediate medical care. Hospitals spend more efforts on reducing the waiting time for patients who spend long time in the waiting areas ${ }^{(6)}$. Patients either their medical condition may deteriorate, or they could get anxious and worried once they wait too long time to receive medical care ${ }^{(7,8)}$. Frustration and eventually anger then happen among patients; a condition which is a difficult task for the medical staff members to deal with ${ }^{(9,10)}$.

\section{MATERIALS AND METHODS}

A cross-sectional study involving 528 participants from all over Saudi Arabia was done during the period from February to March 2018. The selected sample size for this study 
was randomly determined. A self-administered questionnaire was developed after a careful review of literatures on the subject and it included 10 questions. The questionnaires consisted of two parts. Part one; demographical data that includes gender, age and marital status. Part two; the participants were asked whether they have been visiting a public hospital or a private one, what was the main complain that brought them to the hospital and how much time they spent waiting to get help from emergency department health care providers. Participants were also asked if they received a professional health care or not, if they were satisfied of the health care that was provided to them or not, there evaluation to the service and whether the emergency department care can be improved in the future or not. Data were collected by one method through a distribution of a survey website-link through participants living in Saudi Arabia in multiple social media platforms. Descriptive statistics were used to describe the answers of the participants in the study using numbers and percentages.

Comparing the answers for different questions within the different groups was done using Pearson chi-square test. Statistical significance was set at $p<0.05$ and analysis was performed using IBM SPSS statistics, version 23 (IBM, Armonk, NY, USA).

The study was done after approval of ethical board of University of Hail.

\section{RESULT}

A total of 528 participants participated in the study, $72 \%$ were males and $28 \%$ were females (Table 1). More than half of the participants $63.6 \%$ were married and $36.4 \%$ were single (Table 2), Also, $40 \%$ of the participants were between the ages of 20 to 30 years old (Table 3 ). Regarding the hospital that the participants were visiting, $87.3 \%$ of the participants were visiting a public hospital where $12.7 \%$ were visiting a private one (Table 4). The most common complain that brought the participants to the emergency department was in the abdominal area (Table 5). As regarding the time spent waiting for a medical help, $29.5 \%$ had been waiting more than one hour to get help (Table 6). Concerning the general evaluation, $18.8 \%$ of the participants evaluated the emergency department health care as 1 out of ten (Table7).

Table (1): Sex distribution of the participants

\begin{tabular}{|l|l|l|}
\hline Sex & Frequency & Percent \\
\hline Male & 380 & 72 \\
\hline Female & 148 & 28 \\
\hline Total & 528 & 100 \\
\hline
\end{tabular}

Table (2): Marital status of the participants

\begin{tabular}{|l|l|l|}
\hline $\begin{array}{l}\text { Marital } \\
\text { Status }\end{array}$ & Frequency & Percent \\
\hline Married & 336 & 63.6 \\
\hline Single & 192 & 36.4 \\
\hline Total & 528 & 100 \\
\hline
\end{tabular}

Table (3): Age distribution of the participants

\begin{tabular}{|l|l|l|}
\hline Age & Frequency & Percent \\
\hline $0-10$ years & 4 & 0.8 \\
\hline $10-20$ years & 37 & 7 \\
\hline $20-30$ years & 211 & 40 \\
\hline $30-40$ years & 142 & 26.9 \\
\hline $40-60$ years & 116 & 22 \\
\hline$>60$ years & 18 & 3.4 \\
\hline Total & 528 & 100 \\
\hline
\end{tabular}

Table (4): Type of hospital were visited 
Knowledge about Waiting Time Spent in the Emergency Department for Patients...

\begin{tabular}{|l|l|l|}
\hline Type of hospital were visited & Frequency & Percent \\
\hline Public & 461 & 87.3 \\
\hline Private & 67 & 12.7 \\
\hline Total & 528 & 100 \\
\hline
\end{tabular}

Table (5): The main complain area of the body

\begin{tabular}{|l|l|l|}
\hline Area & Frequency & Percent \\
\hline Abdomen & 215 & 42 \\
\hline Chest & 143 & 27.9 \\
\hline Head and neck & 120 & 23.4 \\
\hline Peripheral limbs & 83 & 16.2 \\
\hline Back & 74 & 14.5 \\
\hline Genitalia & 34 & 6.6 \\
\hline Total & 528 & 100 \\
\hline
\end{tabular}

Table (6): Waiting time spent before getting help

\begin{tabular}{|l|l|l|}
\hline Time spent & Frequency & Percent \\
\hline 5 minutes & 45 & 8.5 \\
\hline 10 minutes & 65 & 12.3 \\
\hline 15 minutes & 63 & 11.9 \\
\hline 20 minutes & 58 & 11 \\
\hline 30 minutes & 75 & 14.2 \\
\hline 40 minutes & 66 & 12.5 \\
\hline$>1$ hour & 165 & 29.5 \\
\hline Total & 528 & 100 \\
\hline
\end{tabular}

Table (7): General evaluation out of ten

\begin{tabular}{|l|l|l|}
\hline Evaluating number & Frequency & Percent \\
\hline 1 & 99 & 18.8 \\
\hline 2 & 26 & 4.9 \\
\hline 3 & 59 & 11.2 \\
\hline 4 & 56 & 10.6 \\
\hline 5 & 87 & 16.5 \\
\hline 6 & 44 & 8.3 \\
\hline 7 & 38 & 7.2 \\
\hline 8 & 50 & 9.5 \\
\hline 9 & 31 & 5.9 \\
\hline 10 & 38 & 7.2 \\
\hline Total & 528 & 100 \\
\hline
\end{tabular}

\section{DISCUSSION}

In the present study, $87.3 \%$ of the participants were visiting a public hospital while $12.7 \%$ were visiting a private one. The main complain that brought the patients to the hospital was in the abdominal area with a $42 \%$ while only $6.6 \%$ of the participants complain of back symptoms that brought them to the emergency department. Regarding waiting time in the emergency department, $29.5 \%$ of the participants had been waiting more than one hour before they got helped by healthcare providers, while only $8.5 \%$ of the participants had waited just five minutes to get helped. A study was done by Mohammed Hanaffi Abdullah in a hospital in Malaysia to determine the outpatient department waiting time and to look for the factors which are responsible for patients waiting period in the outpatient department of the hospital. His study revealed that there are multiple factors responsible for waiting period 
such as registration procedure, number of the staff working at the center and insufficient physicians ${ }^{(11)}$. One reason for minimizing nonacceptable waiting is that it is a social necessity since waiting is experiential and can be affected by the actions of the medical staff. The waiting experience may lead to anxiety, worries among both patients and staff members ${ }^{(12,13)}$. An unfamiliar and unknown environment with many ill people in combination with concerns about their own condition make patients at the emergency department get worried and anxious. Therefore, medical staff should pay more attention in providing an immediate care for patients as soon as they enter the waiting room. The patients need the presence of the staff, but also available information since wellinformed patients are calmer. This is part of a process control that is provided in the emergency department ${ }^{(14)}$.

The properties of waiting management that involve covering up to change the patient experience of waiting seem not so well studied systematically. In one study "Covering up for the doctor" was used in physician consultations by interpreters to avoid that threatening information was experienced as coming from the interpreters who can translate the nonunderstandable language in a quick way for patients who speak a different language ${ }^{(15)}$. There were $47.5 \%$ of the participants complaining that they did not receive a professional medical healthcare when visiting the emergency department. Regarding patient's evaluation, $18.8 \%$ of the participants evaluated the emergency department service as one out of ten while only $7.2 \%$ of the participants gave a score of ten out of ten. It turns that waiting time in the emergency departments is increasing significantly not only worldwide but also in Saudi Arabia.

This result would mean that a quick action has to be made by the ministry of health in Saudi Arabia to minimize the time that patients usually spend during the emergency department visit to improve the overall outcomes and to get a higher patients satisfaction.

\section{CONCLUSION}

We can conclude that waiting time at hospitals waiting to receive medical care has been increasing these years all over Saudi Arabia.

Patients are spending so much time before they get a medical care. The ministry of health and emergency departments must play a professional role in reducing the time spent in emergency department and provide a good health care service to the patients who will be satisfied if the waiting time in hospitals during visiting the emergency department timing issue has been reduced to avoid the unpleasant feelings of the patient especially those suffering from serious illness. Ministry of health should give great consideration to assure the satisfaction of every patient seeking rapid emergency medical help all over the day (24 hours service).

\section{REFERENCES}

1. Journal of Institute of Medicine (2006): Hospital-based emergency care: At the breaking point. National Academy of Sciences., Washington, DC.

2. Wilper AP, Woolhandler S, Lasser KE et al. (2008): Waits to see an emergency department physician: U.S. trends and predictors, Health Aff (Millwood).

3. Herring A, Wilper A, Himmelstein DU et al. (2009): Increasing Length of Stay Among Adult Visits to U.S. Emergency Departments, Acad Emerg Med., Available at: https://www.annemergmed.com/article/ S0196-0644(09)01283-9/fulltext

\section{United States Government} Accountability Office (2009): Hospital emergency departments; crowding continues to occur, and some patients wait longer than recommended time frames. https://www.gao.gov/products/GAO-09347

5. E W Nawar, R W Niska, J Xu (2007): National Hospital Ambulatory Medical Care Survey: emergency department summary, Adv Data, 386:1-32.

6. Tony S (2016): How to Reduce Wait Time in the Emergency Room. Available at: http://www.wikihow.com/ReduceWait-Time-in-the-Emergency-Room.

7. Yoon J, Sonneveld M (2010): Anxiety of patients in the waiting room of the emergency department https://dl.acm.org/citation.cfm?id=170994 6.

8. Kihlgren AL, Nilsson M, Skovdahl K et al. (2004): Older patients awaiting 
Knowledge about Waiting Time Spent in the Emergency Department for Patients...

emergency department treatment. Scand J Caring Sci., 18:169-176. doi: 10.1111/j.1471-6712.2004.00266.

9. Winter $\mathbf{N}$ (2000): Waiting: integrating social and psychological perspectives in operations

management. Omega, 28:611-629.

10. Åkerström M (1997): Waiting -- a source of hostile interaction in an emergency clinic. Qual Heal Res., 7:504-520.

11. Abdullah MH (2005): Study on Outpatients Waiting Time in Hospital University of Kebangsaan Malaysia (HUKM) Through the Six Sigma Approach. he Journal of the Department of Statistics, 1:39-53
12. Nairn S, Whotton E, Marshal C et al. (2004): The patient experience in emergency departments: a review of the literature. Accid Emerg Nurs., 12:159165.

13. Nelson D, Coleman K, Walker J (1997): Why are you waiting? Formulating an information pamphlet for use in an accident and emergency department. Accid Emerg Nurs., 5:3941.

14. Naumann S, Miles JA (2001): Managing waiting patients' perceptions: the role of process control. J Manag Med., 15:376-386.

15. Robb N, Greenhalgh T (2006): You have to cover up the words of the doctor: the mediation of trust in interpreted consultations in primary care. J Health Organ Manag., 20:434-455. 